\title{
Research on College Students' Consumption Behavior of Campus Loan under the Internet Economy Based on Guangdong Baiyun University
}

\author{
Qin Feng ${ }^{1, ~}{ }^{*}$, Tiexiong $W u^{1}$ \\ ${ }^{1}$ Guangdong Baiyun University, Guangzhou, 510450, China \\ * Corresponding author: Qin Feng (fitkidssales@fitkits.com.cn)
}

\begin{abstract}
Ant-credit-pay, one of the most famous payment mediums of the internet finance, has become part of people daily life to influence peoples' consumption concept and behavior, especially to college students. This article uses questionnaire analysis, literature research and field research to analyze the factors to use Ant-credit-pay and the effects of using Ant-credit-pay to give the suggestion of correctly to understand and use it.
\end{abstract}

Keywords: Campus Loan, College students' Consumption, Ant Credit pay, Internet Economy.

\section{Introduction}

As the rapid development of the internet finance in recent years, there are a variety of internet financial credit business have been emerged, but the most notable ones is Ant-creditpay. The latest research shows that there are more than 45 million people of 170 million young people born in 1990s in china to be Ant-credit-pay loyal users. Ant-credit-pay has a remarkable achievement with the most convenience for college students 's user experience: to use this month and return next month as well as the super long interest free period. But the subsequent also has a serious of negative influence. This article based on the college students in Guangdong Baiyu University analyzes the influence of using Ant-creditpay to college students' consumption and behavior to guide Baiyun University students to establish the habit of rational consumption and healthy campus consumption culture.

\section{Background}

Accrording to China e-commerce market data release report by IResearch Consulting, the transaction scale of Chinese online shopping market reached 2.1 trillion in 2020Q1, reduced by $0.6 \%$ compared with the same period of 2019 for the covid-19 but still higher than the ratio of total retail sales of social consumer goods at the same period. Chinese first e-commercial C2C born in 1999 has been rapid developing in China until now, such as JD, Tmall etc. It has been gradually involving various service information to be aggregated in internet platform to meet e-commerce of service industry. For examples, there are a set of industries to enter the e-commercial platform such as: real estate services, restaurant business, housekeeping services, medical care, health care etc. It has attracted huge number of consumer groups with its novelty and innovation.

College students, as one of the critical role in the online shopping, play a leading effect in this group so many of them indulge in online loan consumption. In this situation, there are lots of routine loans and campus loans for collage students to surge up. Many collage students have been trapped in the quagmire of huge loans before they began to realize problems.
Many people hate campus loans and they also refuse conspicuous consumption and excessive consumption but as Ant-credit-pay and White Stripe etc online lending platform has the rapid emerging development, more and more college students can not resist the temptation of online loan consumption.

It is reported that there are few college students never use Ant-credit-pay to meet excessive consumption. College students' consumption concept and behavior has been changing imperceptibly.

As new force in the future of our country, college students must establish positive values, practical philosophy and world outlook as well as foster the correct consumption views and behavior.

\section{Analysis Investigation Result}

As the internet economy rapid development, the users of Ant-credit-pay and White Stripe etc newly peer-to-peer have a great increase. Thus in 2019, we set up a team to study college students' consumption behavior of campus loan under the internet economy, based on Guangdong Baiyun University through questionnaire to search the 2000 students but there are 1500 pieces to be effective to be covered all majors of western and northern campuses. The most majority of them are sophomores and juniors and there are more liberal arts students than science students. The results are shown as followings: the living expenses of college students are mainly used for food and daily necessities; this increases the possibility to spend money on other items by Ant-credit-pay.

\subsection{Monthly Expenses and Ant-credit-pay Quota}

Shown from figure 1 , there are $59.14 \%$ of college students to have living expenses between $800-1500$; the second is the $24.25 \%$ for $1500-2000$; the rest is $4.65 \%$ above 2000 . Shown from figure 2, the majority of college students has Ant-creditpay quota of 500-3000. Analyzed these two figures, there is a high degree of overlap between living expenses and Antcredit-pay quota of 500-3000; it means in addition to living expenses, there has been almost double for the cost of living. 


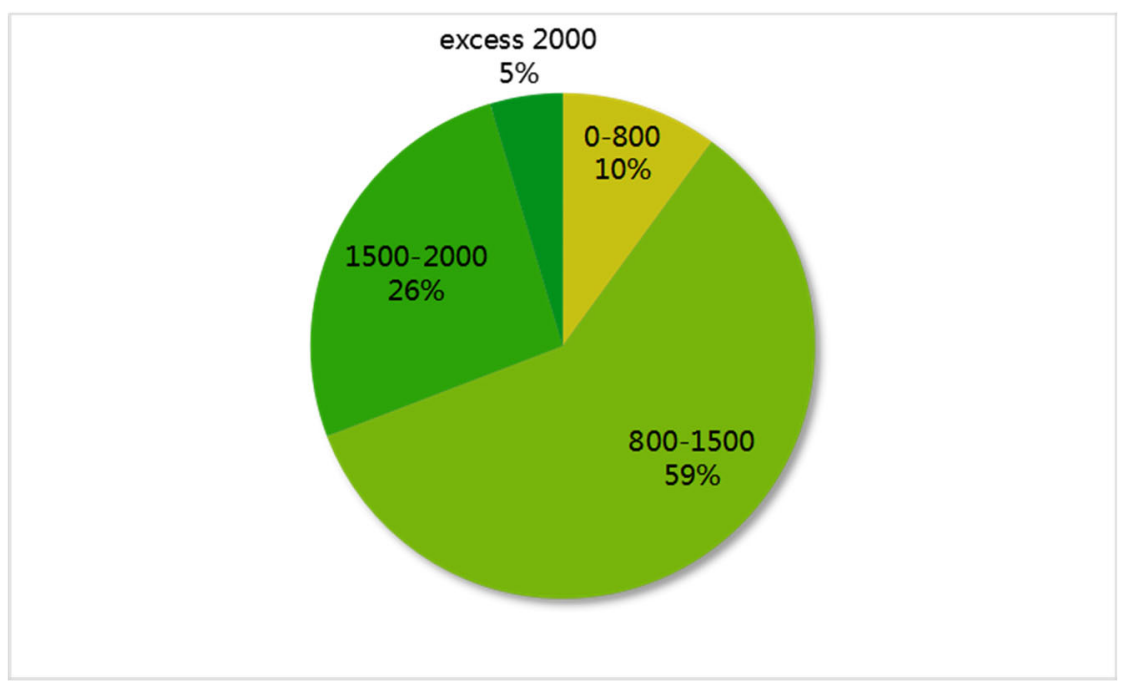

Figure 1. Living expenses for college students

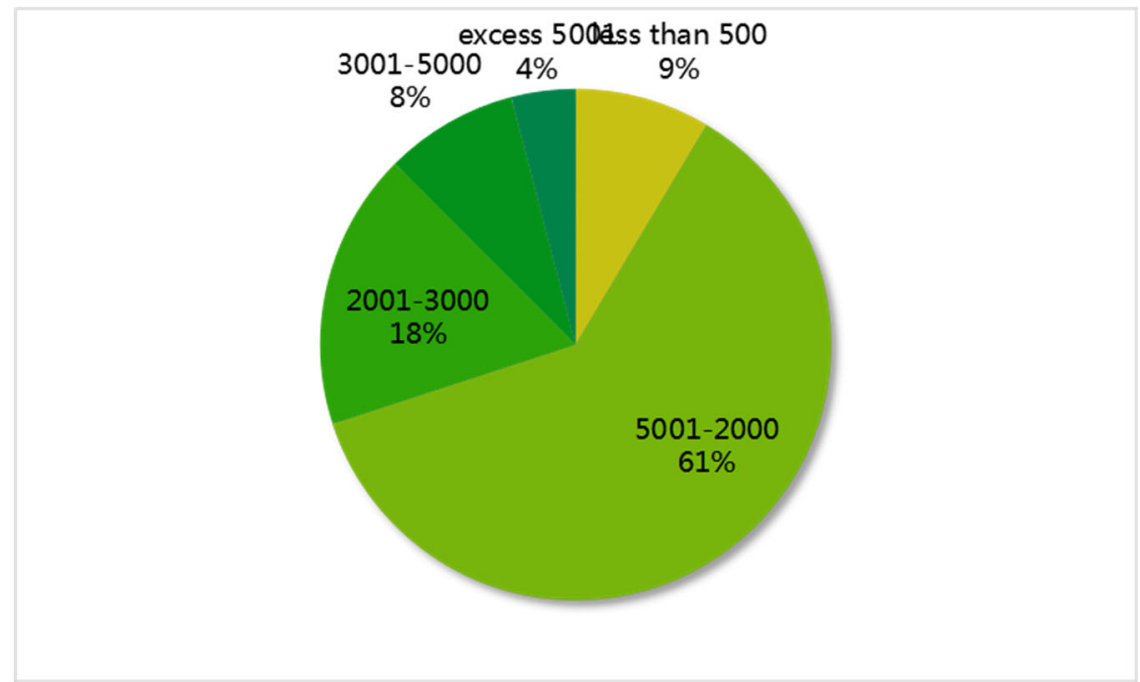

Figure 2. Ant-credit-pay quota for college students

\subsection{The Influence of Ant-credit-pay to College Students' Consumption Structure}

By comparison of proportion chart of main usage of living expenses with main usage of Ant-credit-pay for college students, there is a decreasing of proportion of food, daily necessities and stationery and increasing of proportion of clothes, cosmetics, entertainment as well as some others. This proves Ant-credit-pay has been greatly affecting consumption construction. They have reduced the expenses in basic life consumption and have increased the expenses in entertainment, clothes and ornaments and some other consumer goods. This can be reflected that Ant-credit-pay has expanded the consumption desire of college students.

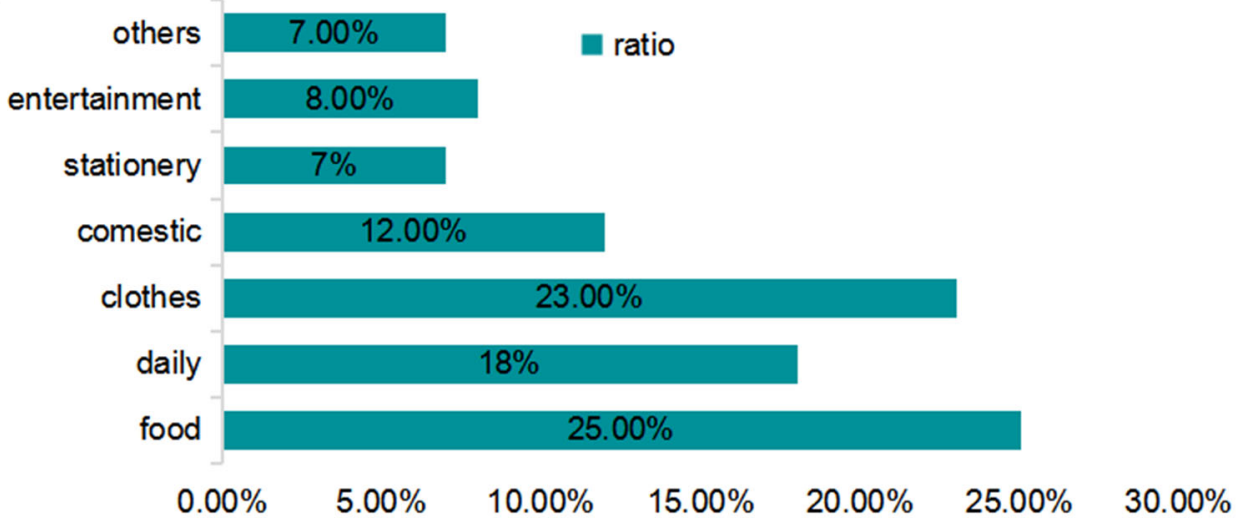

Figure 3. The majority usages of Ant-credit-pay for college students 


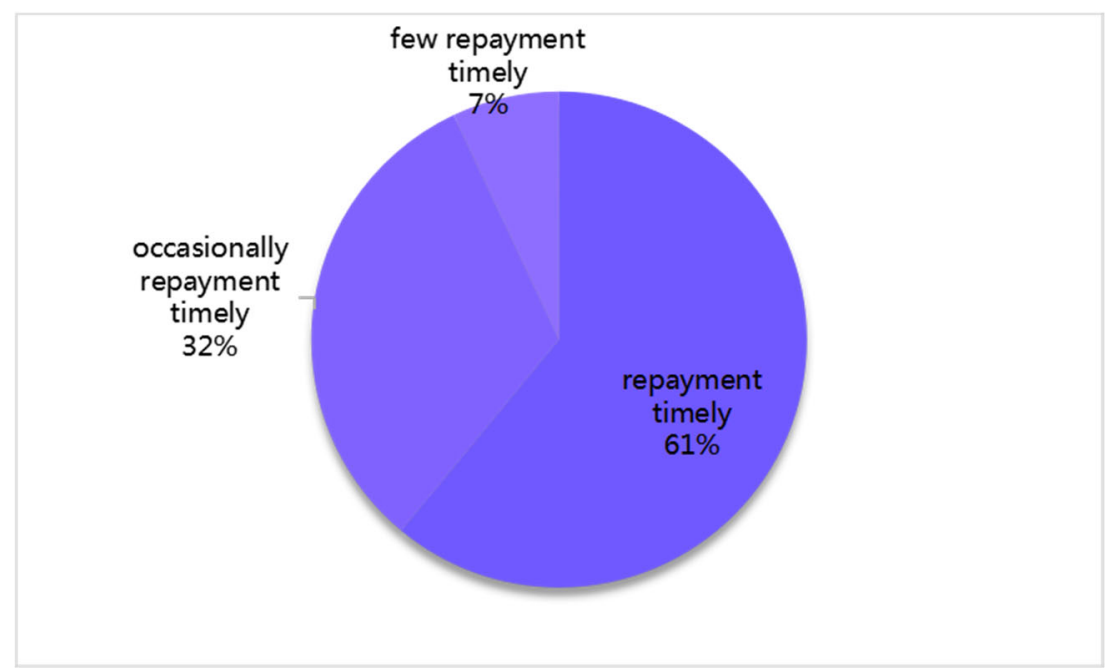

Figure 4. Repayment of Ant-credit-pay

\subsection{Repayment of Ant-credit-pay}

There is the situation if college students afford the loan on time shown from figure 4 . There are over $50 \%$ students has been affording their loan on time but still $30 \%$ college students sometimes don't meet this requirement and even a few of them don't to do timely. Lots of students want to use internet finance to get convenience but there is a very risk situation for some of them overdue. We must take necessary measures to avoid similar phenomena in large scales.

\section{The Reasons of Causing the Bad Consumption Behavior}

\subsection{Social Aspects}

\subsubsection{Culture of Consumerism}

The trend of consumerism has been caused by social media for the market economic forces are entering. College students, one of the most sensitive groups to be influenced by the consumerism; there are full of designed ad to stimulate college students' consumption desire by a simple story, short videos or advertisement. Meanwhile the most top value in internet is to advocate hedonism.

\subsubsection{Simplification of $P 2 P$}

Innovative financial instruments tend to be convenient and diversified with the rapid development of internet finance and the popularization of e-commercial business. Contrary to other $\mathrm{p} 2 \mathrm{p}$, Ant-credit-pay to be one of the most notable for its lower cost, higher safety and more convenience.

First, the lowest requirement to get Ant-credit-pay. According to Ant-credit-pay service, each citizen can get an Ant-credit-pay if they has an effective alipy and are over 18 years old to apply with their identification binding mobile phone.

Second, the Ant-credit-pay with the wide range of application has entered the offline consumer places. At same time Ant-credit-payment has been the preferred payment medium for its red packet function.

Third, Ant-credit-pay has been greatly convenient college students for its models of consumption before payment, deferred payment and bill installments.

\subsubsection{The Infiltration of Commercial Advertisements Into Campus for the Ignorance of University Management as Well as the Lack of the Correct Consumption Concept}

There is no system education of consumption in China; universities don't pay more attention to this part. Commercial advertisement has been infiltrated into campuses to make the campus atmosphere to become impetuous at a certain extent.

\subsection{Family Aspects}

Some of parents fail to guide their kids for their incorrect consumption concepts and behaviors; the others are caused because of parents didn't give them correct consumption view so there is a bad consumption concept for they meet kids all consumption requirements.

\subsection{College Students' Aspects}

In addition to the reasons mentioned in this article, some of college students have limited identification to distinguish the differences between desire and requirement. They don't know how to reasonably arrange their expense and income for lacking of financing consciousness and having unreasonable consumption construction.

\section{The Influences of Anti-Credit-Pay to College Students' Consumption Behavior}

We try to find the most popular consumption concepts in campus by summarizing them. It is undeniable that lot of college students have the correct consumption behavior and they are diligent and thrifty. But we want to find the relationship between incorrect consumption behavior and the use of Ant-credit-pay.

\subsection{Conspicuous Consumption}

Conspicuous consumption, also described as flaunting consumption, is a conception to advocate the behavior of consuming all kind of luxury goods; luxury means status to push the price is far more beyond its value.

The spread of Ant-credit-pay is by the benefit of this tender. It is shown from this questionnaire lots of Anti-credit-pay is used in consumption expense rather than daily living expenses. We can summarized from the investigation that lots of target users in Guangdong Baiyun University are not to meet the daily living expenses.

\subsection{Impulse Consumption}

The group of impulse consumption or blind consumption prefer to be passive consumption for lacking of self identification. They will consumer for a social media ad, or 
friend's reference etc. College students are easy to make blind consumption for they don't have enough experience or they just want to integrate into a group.

Ant-credit-pay offers this kind of students a channel to meet their vanity. They purchase some more goods beyond their financial capability not for necessary but for following suit blindly.

\subsection{Excessive Consumption}

They use the bill installment or consumption before payment of Ant-credit-pay to remedy the deficit of inefficient income. It is reasonable to have appropriate consumption in advance for they can predict their repayment in the latest future.

But there are part of college students to have the absolutely excessive consumption; their loan is completely out of their ability to repay for they continuously to overdraft their credit. Lot of college students are don't have independent income so they need to study the self discipline when they using internet financial tools.

\section{Targeted Suggestions}

\subsection{Ant-credit-pay}

To strengthen vetting mechanism and fulfil loan audit mechanism, Ant-credit-pay have special application for college students to offer relative quota for them.

\subsection{Social Aspects}

It is the primary responsibility to restrict the social media, to encourage ration advertisement, and to establish excellent consumption culture; there should be expanding and strengthen the supervision for social media, especially for Ant-credit-pay etc P2P platform.

\subsection{Family Aspects}

Parents should be setting up a good example with rational consumption and diligent habit as well as refusing blinding consumption; they need to guide their kids to build healthy consumption, to educate their kids to identify the unreasonable consumption and to foster their kids with financing ability.

\subsection{Campus Aspects}

Taken Guangdong Baiyun University for example, as one of the most notable private universities in southern past of China, the university has the obligation to guide their student to have scientific consumption.

First, the university can use the influence of the associations to have relative education activities. For example, there is some positive consumption theme in their major events;
Second, there are a set of methods such as class meeting, lecture or thematic education to influence college students' consumption behavior;

Third, campus commercial advertising should be reasonably controlled;

The last but not the least, the university should pay more attention to campus media to promote the reasonable consumption in the push of daily life.

\subsection{College Students Aspects}

College students are needed to cut their coat according to their cloths and to avoid the conspicuous consumption; they need to consciously improve their financial management ability and to reasonably arrange their expenditure; they also need to adjust their Ant-credit-pay quota according to their ability.

\section{Conclusion}

We learned not only the consumption situation for part of Guangdong Baiyun University but also get some generality by studying lots of literature and analyzing a huge of data. No matter which part of consumption (conspicuous, blind or excessive consumption), there is a great potential threat for college students. Contemporary students are so important for family and nation that they must have healthy consumption behavior.

We don't deny the most convenience to be linked by Antcredit-pay so it is not Ant-credit-pay misguide the college students to have incorrect consumption behavior. We need to guide them to have ration consumption concept to establish correct consumption behavior.

\section{Acknowledgment}

Financial Support: This article is under the construction projects of key disciplines Applied Economics College of Guangdong Baiyun University China.

\section{References}

[1] Ye Yize, Jia Feixiang. Analysis and Countermeasures of the College Students' Campus Loan -- Taken Anti-credit-pay for example [J]. Economic Research Guide, 2020(23): 63-64.

[2] Yu Yingxin, Li Huijun. Research on the P2P for College Students based on Internet+ [J].Journal of Beijing Institute of Graphic Communication, 2021(1): 110-114.

[3] Zhang Xianping. Research on Situation, Problems \& Countermeasures of Excessive Consumption [J].Modern Business Trade Industry, 2021(5): 87-88.

[4] Jiang Wenjing. Research on the Influence of Campus Loan of Ant-credit-pay for College Students[J]. Consumer Market, 2020: 63-64. 